Research Paper

\title{
The Effect of Nefopam Infusion during Laparascopic Cholecystectomy on Postoperative Pain
}

Eun Mi Kim, Joo Hyun Jeon, Mi Hwa Chung, Eun Mi Choi, Seung Hwa Baek, Pil Hyun Jeon, Mi Hyeon Lee ${ }^{\bowtie}$

Department of Anesthesiology and Pain Medicine, Kangnam Sacred Heart Hospital, Hallym University College of Medicine, Seoul, Republic of Korea

$\square$ Corresponding author: Mi Hyeon Lee, M.D., Ph.D., Department of Anesthesiology and Pain Medicine, Kangnam Sacred Heart Hospital, Hallym University College of Medicine, 948-1, Daerim 1-dong, Yeongdeungpo-gu, Seoul, 150-950, Korea. Phone: +82-2-829-5230, Fax: +82-2-845-1571, E-mail: md1212@naver.com

(C) Ivyspring International Publisher. This is an open access article distributed under the terms of the Creative Commons Attribution (CC BY-NC) license (https://creativecommons.org/licenses/by-nc/4.0/). See http://ivyspring.com/terms for full terms and conditions.

Received: 2017.01.03; Accepted: 2017.03.29; Published: 2017.05.05

\begin{abstract}
Background: While recovery from remifentanil is fast due to its rapid metabolism, it can induce hyperalgesia by activation of $\mathrm{N}$-methyl-D-aspartic acid (NMDA) receptors. Therefore, administration of NMDA receptor antagonists such as ketamine is effective in relieving hyperalgesia caused by remifentanil. A previous study showed that nefopam administration before anesthesia combined with low-dose remifentanil reduced pain and analgesic consumption during the immediate postoperative period. We hypothesized that intraoperative infusion of nefopam during laparoscopic cholecystectomy would be as effective as ketamine in controlling pain during the acute postoperative period after sevoflurane and remifentanil based anesthesia.

Methods: Sixty patients scheduled to undergo laparoscopic cholecystectomy were randomly divided into three groups. General anesthesia was maintained with sevoflurane and effect-site target concentration of remifentanil $(4 \mathrm{ng} / \mathrm{ml})$ in all patients. An intravenous bolus of nefopam $(0.3$ $\mathrm{mg} / \mathrm{kg}$ ) was given, followed by continuous infusion $(65 \mu \mathrm{g} / \mathrm{kg} / \mathrm{h})$ in Group $N(\mathrm{n}=20)$. An intravenous bolus of ketamine $(0.3 \mathrm{mg} / \mathrm{kg})$ was administered, followed by continuous infusion $(180 \mu \mathrm{g} / \mathrm{kg} / \mathrm{h})$ in Group K ( $n=20)$, and Group $C$ received a bolus and subsequent infusion of normal saline equal to the infusion received by Group K $(n=20)$. We compared postoperative Visual Analogue Scale (VAS) scores and analgesic requirements over the first 8 postoperative hours between groups.

Results: The pain scores (VAS) and fentanyl requirements for $1 \mathrm{~h}$ after surgery were significantly lower in the nefopam and ketamine groups compared with the control group $(p<0.05)$. There were no differences between the nefopam and ketamine groups. The three groups showed no differences in VAS scores and number of analgesic injections from 1 to $8 \mathrm{~h}$ after surgery.

Conclusion: Intraoperative nefopam infusion during laparoscopic cholecystectomy reduced opioid requirements and pain scores (VAS) during the early postoperative period after remifentanil-based anesthesia.
\end{abstract}

Key words: Hyperalgesia, Nefopam, Ketamine, Postoperative pain, Remifentanil.

\section{Introduction}

Laparoscopic cholecystectomy causes less postoperative pain than open cholecystectomy. However, pain control after laparoscopic cholecystectomy remains an unresolved issue [1, 2]. In laparoscopic cholecystectomy, short-acting opioids such as remifentanil are recommended for reducing the surgical stress response [2].
Patients recover quickly from remifentanil due to its rapid metabolism [3]; therefore, it is effective in preventing several opioid side effects, including respiratory depression [4]. However, remifentanil can induce hyperalgesia, and may trigger severe postoperative pain $[5,6]$. Such hyperalgesia is caused by activation of $N$-methyl-D-aspartic acid (NMDA) 
receptors. Therefore, administration of an NMDA receptor antagonist such as ketamine is effective in relieving the hyperalgesia caused by remifentanil $[7,8]$.

Nefopam is a non-opioid analgesic that inhibits monoamine reuptake in the central nervous system [9]. In rats, nefopam indirectly modulates the NMDA receptor, decreasing c-Fos expression in the dorsal horn of the spinal cord and relieving allodynia and opioid-related hyperalgesia [10]. In addition, nefopam administered in combination with low-dose remifentanil before anesthesia was shown to display a postoperative analgesic efficacy during the acute phase and reduced analgesic requirements [11]. However, compared to intraoperative ketamine infusion with remifentanil-based anesthesia in laparoscopic cholecystectomy patients, the postoperative analgesic efficacy of nefopam infusion during surgery remains unclear [12].

We aimed to examine the postoperative analgesic efficacy of intraoperative nefopam infusion in patients undergoing laparoscopic cholecystectomy. We hypothesized that nefopam infusion during laparoscopic cholecystectomy was as effective as ketamine infusion for controlling pain caused by remifentanil infusion during the acute postoperative period.

\section{Methods}

\section{Patients and study design}

This prospective, randomized, placebocontrolled double blinded study was conducted after obtaining approval from our institutional review board, and is registered at clinical trials.gov (NCT02493231). This manuscript adheres to applicable EQUATOR guidelines. Written informed consent was obtained from all patients. Data were collected between July and December 2015. We selected 60 patients, aged 20-65 years, American Society of Anesthesiologists physical status 1 or 2 who were scheduled to laparoscopic cholecystectomy under general anesthesia. Exclusion criteria were as follows: patients with hepatic disease, kidney disease, diabetes, cardiovascular disease, airway related disease, recent use of opioids or beta blocking agents, or a known allergy to drugs. A list of random numbers generated by Microsoft Excel (Microsoft Co., Redmond, WA, USA) was used to randomize patients into three groups. Patients were randomly assigned to receive remifentanil and nefopam ( $\mathrm{N}$ group), remifentanil and ketamine (K group), or remifentanil and normal saline ( $\mathrm{C}$ group) during surgery.

\section{Anesthetic Procedures}

Three medical staff conducted the study, in the induction of anesthesia, anesthetic maintenance, and postoperative pain assessment. One anesthesiologist who participated in the study design was responsible for induction of general anesthesia and was not involved in other parts of the study process. Another anesthesiologist, who was blinded to patient grouping, performed maintenance of anesthesia. Postoperative pain assessment was performed by another nurse who was also blinded to patient grouping. As premedication, patients received midazolam (2 $\mathrm{mg})$ and glycopyrrolate $(0.2 \mathrm{mg}$ intramuscularly). Upon arrival to the operating room, patients underwent standardized monitoring of non-invasive blood pressure, heart rate, oxygen saturation, and electrocardiography. In addition, the BIS (Bispectral Index Monitor, Aspect Medical Systems, Inc., Newton, MA, USA) was used, and the baseline value for all equipment were obtained. After pre-oxygenation with $100 \%$ oxygen, anesthesia was induced with propofol $(2 \mathrm{mg} / \mathrm{kg})$ and an effect-site target concentration of remifentanil $(4 \mathrm{ng} / \mathrm{ml})$ was infused using an Orchestra pump (Orchestra Infusion Workstation, Frenius Vial, France). After the effect-site target concentration of $4 \mathrm{ng} / \mathrm{ml}$ was reached, we confirmed loss of consciousness by verbal stimuli or eyelid reflex. Subsequently, rocuronium $(0.6 \mathrm{mg} / \mathrm{kg})$ was administered and when the jaw was relaxed tracheal intubation was performed approximately 2 minutes later.

Two unlabeled syringes were prepared. For the first dose, a 20-ml syringe containing the study drug $(0.4 \mathrm{mg} / \mathrm{ml}$ of nefopam or $1 \mathrm{mg} / \mathrm{ml}$ of ketamine) or normal saline (placebo) was used. For continuous infusion, a second 50-ml syringe containing the same concentration of study drug or isotonic saline was used. Based on a previous study [13], group $\mathrm{N}$ received intravenous nefopam $(0.3 \mathrm{mg} / \mathrm{kg})$ during anesthesia induction and nefopam $(65 \mu \mathrm{g} / \mathrm{kg} / \mathrm{h})$ was infused continuously during surgery. Also, based on a previous study [14], group $\mathrm{K}$ received intravenous ketamine $(0.3 \mathrm{mg} / \mathrm{kg})$ during anesthesia induction, and ketamine $(180 \mu \mathrm{g} / \mathrm{kg} / \mathrm{h})$ was infused continuously during surgery. Group $C$ received normal saline at the same infusion rate as Group $\mathrm{K}$. Anesthesia was maintained with 1.5-3.5 vol\% sevoflurane, which was adjusted to maintain a BIS of 40-60, and remifentanil was maintained with an effect-site target concentration of $4 \mathrm{ng} / \mathrm{ml}$ in all three groups. After induction and setting up the maintenance of anesthesia, the anesthesiologist was replaced by another anesthesiologist who was blinded to group assignments to maintain anesthesia per study protocol. When the blood pressure decreased 
more than $20 \%$ of the baseline value, intravenous ephedrine $(4 \mathrm{mg})$ was administered; intravenous atropine $(0.5 \mathrm{mg})$ was utilized to treat heart rates less than 45 beats per minute (bpm). For blood pressure increases of more than $20 \%$ of the baseline value, intravenous nicardipine $(6 \mu \mathrm{g} / \mathrm{kg})$ was given. Any changes in the patient's hemodynamic or respiratory conditions were managed promptly and recorded.

Before incisional closure, fentanyl $(1 \mu \mathrm{g} / \mathrm{kg}$, maximum dose $100 \mu \mathrm{g})$ and ramosetron $(0.3 \mathrm{mg})$ were injected intravenously. After completion of closure, sevoflurane and remifentanil, and all study drugs such as nefopam, ketamine, or normal saline were also discontinued. For reversal of neuromuscular relaxation, glycopyrrolate $(0.4 \mathrm{mg})$ and pyridostigmine $(20 \mathrm{mg})$ were injected and manual ventilation with $100 \%$ oxygen was performed with 35-45 $\mathrm{mmHg}$ end-tidal carbon dioxide concentration.

When patients responded to verbal commands and opened his or her eyes, and there was sufficient antagonism or the tidal volume was appropriate, the patient was extubated and moved to the post-anesthesia care unit (PACU). Perioperative hemodynamic data such as blood pressure, heart rate, oxygen saturation, and perioperative drug administration were recorded and the total amount of the remifentanil, nefopam, and ketamine administered during surgery were recorded. Time from expired $0.3 \mathrm{vol} \%$ sevoflurane to the time of awakening and extubation were measured.

\section{Postoperative pain management and patient assessments}

In the PACU, hemodynamic parameters, visual analogue scale $(\mathrm{VAS}, 0=$ no pain, $10=$ most severe possible pain), nausea, vomiting, sedation score, other complications, and analgesic administration were recorded at 5-min intervals for $1 \mathrm{~h}$. Intravenous fentanyl $(50 \mu \mathrm{g})$ was given when the patient's VAS score was greater than 4 ; after 15 min the pain score was reevaluated. If the VAS score was still greater than 4 , intravenous fentanyl $(25 \mu \mathrm{g})$ was injected. A follow- up pain evaluation was repeated 15 min later, and fentanyl $(25 \mu \mathrm{g})$ was administered for VAS scores remaining above 4. Additional analgesics were administered when deemed necessary. When the heart rate decreased to less than $50 \mathrm{bpm}$, intravenous glycopyrrolate $(0.2 \mathrm{mg})$ was administered and when the systolic or diastolic blood pressure was higher than $180120 \mathrm{mmHg}$, respectively, intravenous nicardipine $(6 \mu \mathrm{g} / \mathrm{kg})$ was given. When the blood pressure decreased more than $20 \%$ from threshold, intravenous ephedrine $(4 \mathrm{mg})$ was administered. When nausea and vomiting developed, antiemetic drugs were utilized.
When patients were moved to the general ward from the PACU, the ward nurse, who was blinded to group assignment, assessed and recorded hemodynamic parameters and pain score (VAS), nausea and vomiting, sedation score, other complications, and the type and amount of analgesic administration until $8 \mathrm{~h}$ postoperatively. When the VAS score was greater than 4 , intravenous tramadol (50 mg) was administered. After $30 \mathrm{~min}$, if the VAS was still greater than 4, additional analgesics (tramadol $25 \mathrm{mg}$ ) were given. After $1 \mathrm{~h}$, the VAS score was reevaluated, and additional analgesics were administered if the VAS score was greater than 4 . This assessment was continued if patients complained of pain. The surgery department made the decisions regarding type and amount of additional analgesic administration and this was recorded during the study period.

The primary outcome measure was VAS score in the PACU. Secondary outcome measurements were total intravenous fentanyl dose in the PACU, time elapsed between intraoperative fentanyl bolus and the first analgesic request in the PACU, presence of postoperative nausea and vomiting (PONV), sedation status during the study period, VAS score in the ward, and total analgesic requirements in the ward.

\section{Statistical Analysis}

All statistical analyses were performed using SAS version 9.2 (SAS Institute Inc., Cary, NC, USA). Comparisons for each demographic and clinical variable among the three groups were performed using the analysis of variance (ANOVA) test for normally distributed variables or the Kruskal-Wallis test for non-normally distributed variables. The chi-squared test or Fisher's exact test were performed for categorical variables. The ANOVA test and Kruskal-Wallis test were performed to compare VAS scores and fentanyl requirements between the three groups at each time point after surgery, respectively, with post-hoc analysis. The changes in VAS, analgesic-free time, and fentanyl consumption over time were analyzed using a linear mixed model considering repeated measurements. Data were expressed as the mean \pm standard deviation and a p-value of less than 0.05 was considered statistically significant. The sample size estimate was based on a previous study [15]. We assumed that mean VAS scores in group $\mathrm{N}$, group $\mathrm{K}$ and group $\mathrm{C}$ were 3.6, 3.6, and 5.5, respectively with a standard deviation of 2.0 and the calculated sample size for each group was 18 ( $\alpha=0.05, \beta=0.8$ ). Therefore, 20 subjects were included in each group considering a $10 \%$ drop-out rate. 


\section{Results}

There were 60 patients who participated in this study; no one was excluded (Figure 1). Table 1 shows the comparison between the three groups in terms of demographic characteristics, operative and anesthesia duration, and the amount of remifentanil injected during surgery. There was no difference in the dose of additional medications during surgery. However, the three groups showed differences in the time between the moment when sevoflurane was measured from 0.3 vol\% expiratory concentration to patient awakening. Group $\mathrm{K}$ showed longer times than Group $\mathrm{N}$ and Group C $(p=0.013, p<0.001)$, while there was no difference between Group N and Group C ( $p=0.145)$.

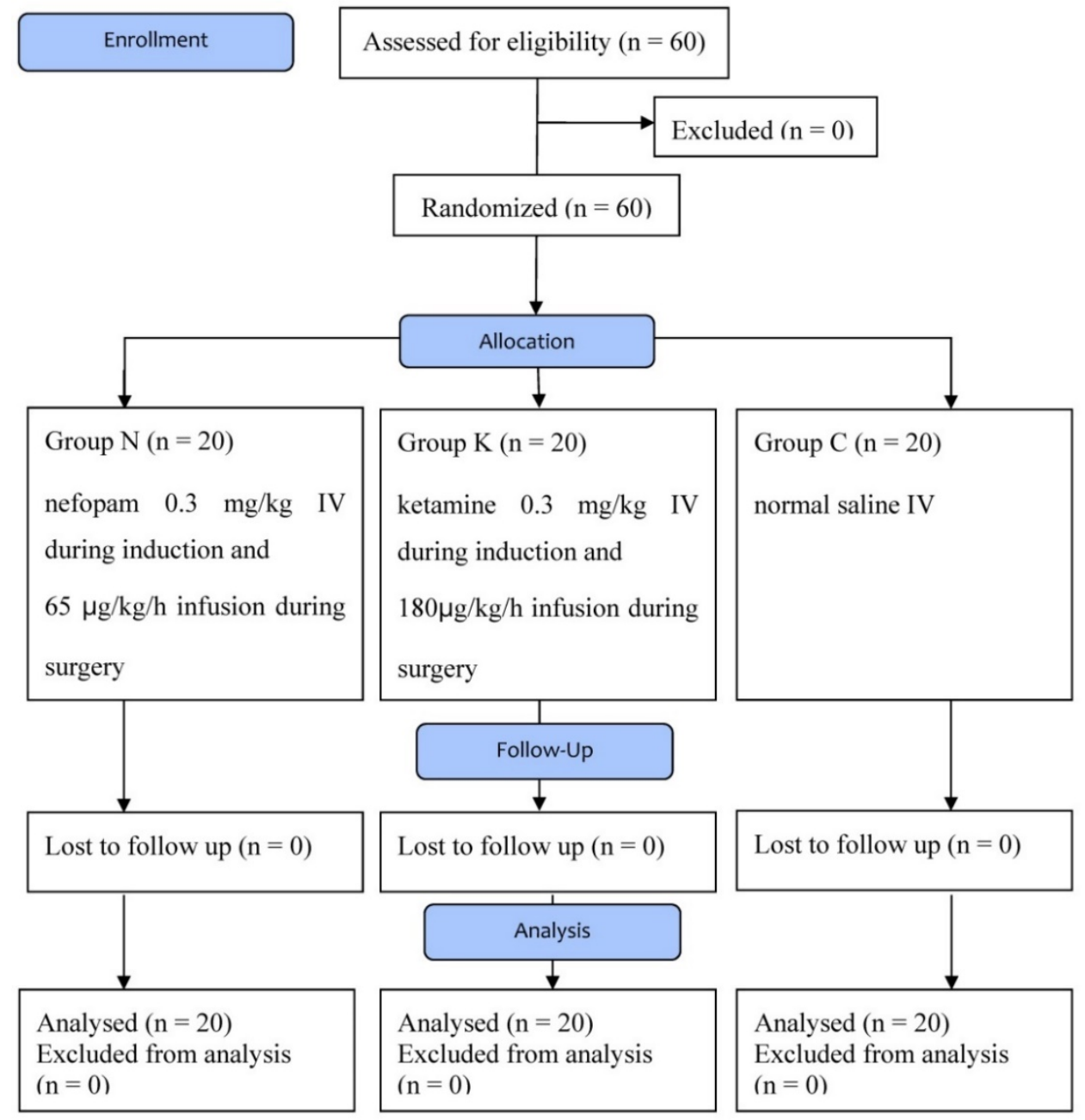

Figure 1. Flow diagram Group C, control group; Group N, nefopam group; Group K, ketamine group

Table 1. Characteristics of Patients and Anesthesia.

\begin{tabular}{|c|c|c|c|c|}
\hline & Group N $(n=20)$ & Group K $(n=20)$ & Group C $(n=20)$ & Overall P-value \\
\hline Age (yr) & $40.8 \pm 12.1$ & $43.0 \pm 11.7$ & $47.2 \pm 11.3$ & 0.223 \\
\hline $\operatorname{Sex}(M / F)$ & $6 / 14$ & $10 / 10$ & $6 / 14$ & 0.317 \\
\hline Body mass index $(\mathrm{BMI})\left(\mathrm{kg} / \mathrm{m}^{2}\right)$ & $24.2 \pm 2.6$ & $24.7 \pm 2.8$ & $23.7 \pm 3.2$ & 0.557 \\
\hline Operation time (min) & $86.8 \pm 28.8$ & $100.3 \pm 30.7$ & $100.3 \pm 30.7$ & 0.091 \\
\hline Anesthesia time (min) & $153.3 \pm 33.2$ & $160.3 \pm 31.8$ & $160.3 \pm 31.8$ & 0.471 \\
\hline Sevo $0.3(\mathrm{~min})^{*}$ & $3.7 \pm 1.5$ & $5.0 \pm 1.9^{*}$ & $2.9 \pm 1.2$ & $<0.001$ \\
\hline Total amount of remifentanil $(\mu \mathrm{g})$ & $558.7 \pm 115.0$ & $559.8 \pm 192.2$ & $602.1 \pm 162.2$ & 0.621 \\
\hline Total amount nefopam (mg) & $22.3 \pm 3.2$ & - & - & \\
\hline Total amount ketamine (mg) & - & $31.6 \pm 8.1$ & - & - \\
\hline
\end{tabular}

Abbreviations: Sevo $0.3(\mathrm{~min})$, time taken from measuring $0.3 \mathrm{vol} \%$ sevoflurane in patient expiration to patient awakening.

Values are presented as the mean \pm standard deviation. There were significant differences among the three groups in the time taken from measuring 0.3 vol\% sevoflurane in patient expiration to patient awakening $\left({ }^{*} \mathrm{p}<0.001\right)$. The Group $\mathrm{K}$ took more time than the group $\mathrm{N}$ and group $\mathrm{C}(\mathrm{p}=0.013, \mathrm{p}<0.001)$, while the Group $\mathrm{N}$ and Group $\mathrm{C}$ showed no significant difference $(\mathrm{P}=0.145)$ (post-hoc test). 
During surgery, there was no significant difference in blood pressure, heart rate, and oxygen saturation between groups. This finding was the same during the $8 \mathrm{~h}$ period after surgery. During the first hour after surgery in the PACU, Group N and Group $\mathrm{K}$ had lower average VAS scores than Group $\mathrm{C}$ $\left({ }^{*} p<0.001\right.$ and 0.033 , Figure 2). Group $N$ had lower VAS scores than Group C at the 1, 5, and 45 min time points in the PACU $\left({ }^{*} \mathrm{p}=0.001,0.026\right.$, and $<0.001$; Figure 2). Group K had lower VAS scores than Group $\mathrm{C}$ at the 1 and $5 \mathrm{~min}$ time points in the PACU $\left({ }^{*} p=0.011,0.034\right.$, Figure 2). Patients in Group N also showed lower VAS scores than Group $\mathrm{K}$ at 5 and 45 minutes, as well as lower average VAS scores in the PACU ( $† p=0.046,0.002$, and 0.009; Figure 2). Group N $(36.3 \pm 37.6 \mu \mathrm{g})$ and Group K $(52.8 \pm 37.3 \mu \mathrm{g})$ had less fentanyl requirements after surgery than Group C $(76.3 \pm 31.9 \mu \mathrm{g}) \quad(\mathrm{p}=0.001,0.042)$. No statistically significant difference was observed between Group N and Group $\mathrm{K}$ in terms of fentanyl requirements for $1 \mathrm{~h}$ after surgery in the PACU (Table 2). Patients in Group $C$ had a shorter time to the first fentanyl injection than Group N and Group K ( $<<0.001, p=0.002$, post-hoc test; Table 2).

The three groups showed no differences in pain scores (VAS) between 1 and $8 \mathrm{~h}$ after surgery (Figure 3). However, patients in Group $\mathrm{N}$ had fewer analgesic injections 1 to $2 \mathrm{~h}$ after surgery compared to Group $\mathrm{K}$ and Group C ( $p=0.018,0.003$, post-hoc test; Table 3). The three groups showed no significant differences in the number of analgesic injections from 2 to $8 \mathrm{~h}$ after surgery (Table 3 ).

When intraoperative nefopam was administered, no tachycardia or profuse sweating developed, and no groups had hemodynamic or respiratory disorders, excessive sedation, or PONV after surgery.

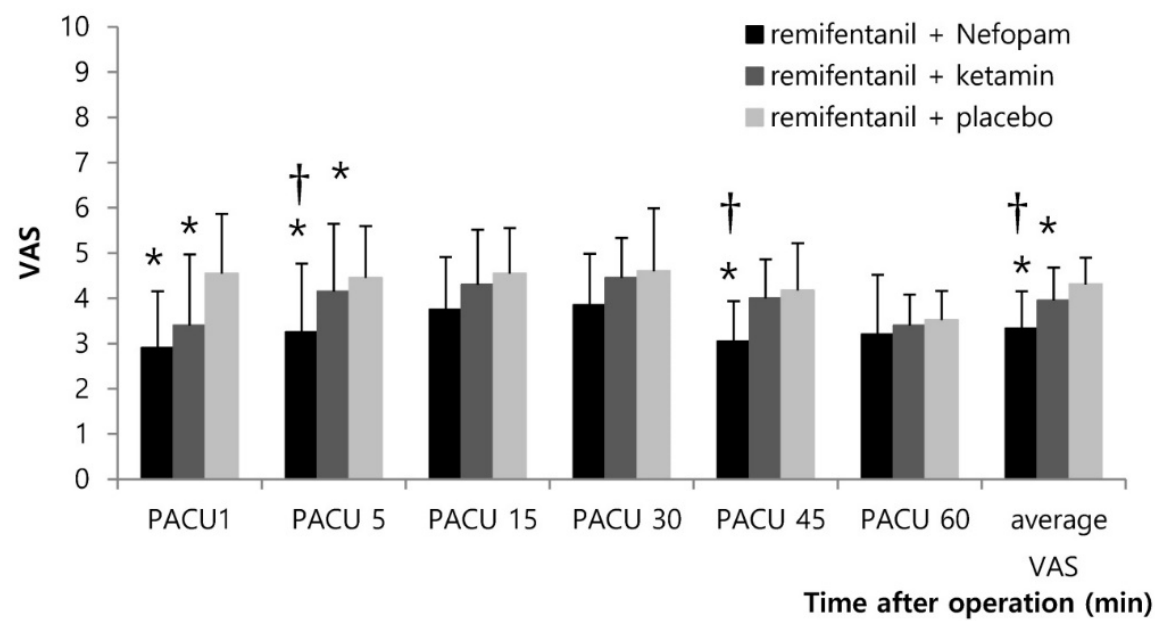

Figure 2. Postoperative pain scores up to first $\mathbf{l} \mathbf{~}$ in PACU. Abbreviations: PACU, post-anesthesia care unit; VAS, visual analogue scale. Values are presented as the mean \pm standard deviation. Group $N$ and Group K had lower average VAS scores than Group C $(* p<0.001$ and 0.033$)$. Group N had lower VAS scores than Group $C$ at the 1, 5, and 45 min time points in the PACU ( ${ }^{p}=0.001,0.026$, and $<0.001$ ). Group K had lower VAS scores than Group $C$ at the 1 and 5 min time points in the PACU $\left({ }^{*}=0.011,0.034\right)$. Patients in Group N also showed lower VAS scores than Group K at 5 and 45 minutes, as well as lower average VAS scores in the PACU $(\dagger P=0.046,0.002$, and 0.009$)$.

Table 2. Total fentanyl requirement and Time to the first fentanyl demand during $1 \mathrm{~h}$ after surgery in PACU.

\begin{tabular}{|c|c|c|c|c|}
\hline & Group N (n = 20) & Group K $(n=20)$ & Group C $(n=20)$ & Overall P-value \\
\hline Total fentanyl requirement $(\mu \mathrm{g})$ & $36.3 \pm 37.6^{*}$ & $52.8 \pm 37.3^{*}$ & $76.3 \pm 31.9$ & 0.003 \\
\hline Time to the first fentanyl demand (min) & $39.5 \pm 22.7^{*}$ & $27.7 \pm 22.4^{*}$ & $7.6 \pm 13.5$ & $<0.001$ \\
\hline
\end{tabular}

Abbreviations: PACU, post-anesthesia care unit. Values are presented as the mean \pm standard deviation. The time to the first fentanyl demand was defined as the time elapsed between intraoperative fentanyl bolus and the first analgesic request in the PACU. Group N $(36.3 \pm 37.6 \mu \mathrm{g})$ and Group K $(52.8 \pm 37.3 \mu \mathrm{g})$ had less fentanyl requirements after surgery than Group C $(76.3 \pm 31.9 \mu \mathrm{g})(\mathrm{p}=0.001, \mathrm{p}=0.042)$. No statistically significant difference was observed between Group $\mathrm{N}$ and Group $\mathrm{K}$ in terms of fentanyl requirements for $1 \mathrm{~h}$ after surgery in the PACU. Patients in Group C had a shorter time to the first fentanyl injection than Group N and Group K ( $\mathrm{p}<0.001, \mathrm{p}=0.002)$ (post-hoc test).

Table 3. The number of patients received analgesics from 1 to $8 \mathrm{~h}$ after surgery.

\begin{tabular}{llll}
\hline patients received analgesics & Group N (n=20) & Group K (n=20) & Group C (n=20) \\
\hline $1-2 \mathrm{~h}$ & $3(15.00 \%)^{*} \dagger$ & $10(50.00 \%)$ & $12(60.00 \%)$ \\
$2-4 \mathrm{~h}$ & $3(15.00 \%)$ & $6(30.00 \%)$ & $1(5.00 \%)$ \\
$4-6 \mathrm{~h}$ & $3(15.00 \%)$ & $3(15.00 \%)$ & $3(15.00 \%)$ \\
$6-8 \mathrm{~h}$ & $1(5.00 \%)$ & $1(5.00 \%)$ & 0.010 \\
\hline
\end{tabular}

Values are expressed as number (\%). Patients in Group $\mathrm{N}$ had fewer analgesic injections 1 to $2 \mathrm{~h}$ after surgery compared to Group $\mathrm{K} \dagger$ and $\mathrm{Group} \mathrm{C}^{*}$ ( $\dagger \mathrm{p}=0.018,{ }^{*} \mathrm{p}=0.003$, post-hoc test). The three groups showed no significant differences in the number of analgesic injections from 2 to $8 \mathrm{~h}$ after surgery. 


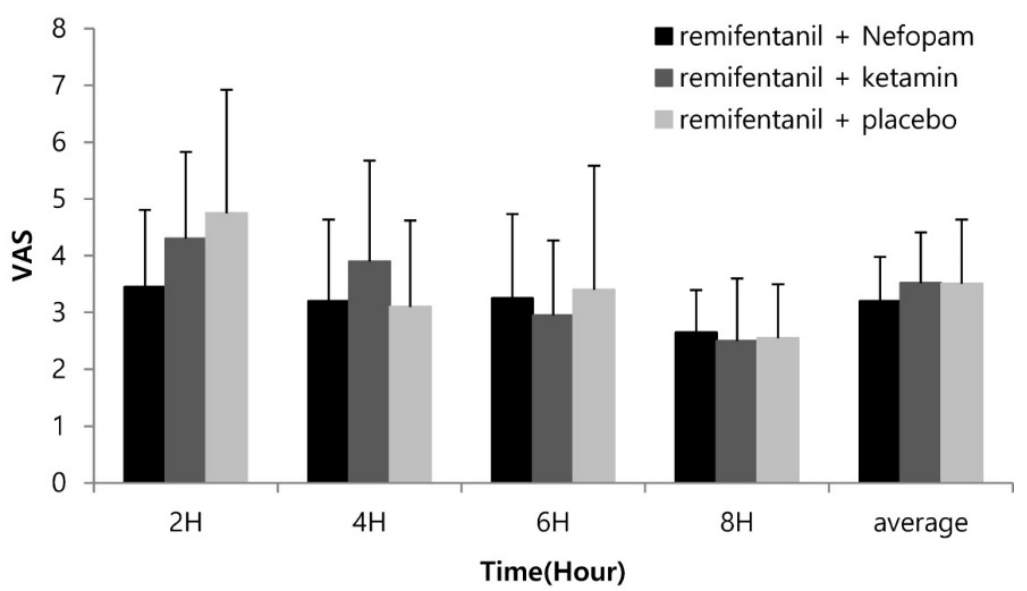

Figure 3. Postoperative pain scores up to $\mathbf{8} \mathbf{~}$ after surgery in the ward. Abbreviations: VAS, visual analogue scale. Values are presented as the mean \pm standard deviation. No significant differences were observed among the three groups $(p>0.05)$.

\section{Discussion}

In this randomized controlled study, patients in the intraoperative nefopam infusion group (Group N) showed reductions in VAS scores and opioid requirements for $1 \mathrm{~h}$ after laparoscopic cholecystectomy with a target controlled infusion of 4 $\mathrm{ng} / \mathrm{ml}$ of remifentanil. This was not a different finding from the group injected with ketamine (Group $\mathrm{K})$, a known NMDA receptor antagonist that prevents opioid-induced hyperalgesia.

We evaluated patients undergoing laparoscopic cholecystectomy who received an effect site concentration of $4 \mathrm{ng} / \mathrm{ml}$ of intravenous remifentanil. Remifentanil is a rapid-acting opioid with a short action time and substantial effects; it effectively controls pain and reduces unwanted cardiovascular reactions [16]. In addition, remifentanil with an anesthetic-sparing effect may result in rapid consciousness after laparoscopic cholecystectomy [17]. However, some studies found that remifentanil is associated with acute tolerance and hyperalgesia. In one study [18], intravenous remifentanil with a 3-4 $\mathrm{ng} / \mathrm{ml}$ effect-site concentration for 60 to $100 \mathrm{~min}$ led to a $180 \%$ rise in capsaicin-induced hyperalgesia. Luginbühl et al. [19] argued that remifentanil with a 3-4 $\mathrm{ng} / \mathrm{ml}$ effect-site concentration can cause hyperalgesia. Joly et al. [8] stated that determining the appropriate amount of remifentanil used during surgery is critical in post-surgery pain control. Although whether remifentanil triggers hyperalgesia remains controversial, NMDA receptor activation is known to play a critical role [20].

Ketamine is an NMDA receptor antagonist that attenuates opioid-induced hyperalgesia [14, 21, 22]. In our present study, patients in Group K continuously received a low dose of ketamine known to prevent remifentanil-induced hyperalgesia. A bolus of ketamine $(0.3 \mathrm{mg} / \mathrm{kg})$ was injected intravenously at induction followed by a continuous infusion of ketamine $(3 \mathrm{mcg} / \mathrm{kg} / \mathrm{min})$ [14]. Compared with the control group (Group C, receiving normal saline), there were no differences observed in blood pressure, heart rate, or oxygen saturation during and after surgery in Group K. There were also no differences in postoperative sedation, hallucinations, or PONV in the PACU or the ward. However, for $1 \mathrm{~h}$ after surgery, Group K showed lower VAS scores and decreased fentanyl requirements than Group C. These results indicate that ketamine is effective for a shorter period than shown in a previous study [14], which used the same dose but demonstrated a drop in pain scores and patient-controlled analgesia (PCA) requirements for $180 \mathrm{~min}$. However, in the abovementioned study, intravenous PCA including morphine and ketorolac was also used to control post-surgery pain. The three groups of our present study received $1.0 \mu \mathrm{g} / \mathrm{kg}$ of fentanyl just prior to the end of surgery. As patients in our present study received a fentanyl bolus injection according to the study protocol, reduced pain scores and fentanyl requirements were found for only an hour after surgery.

Nefopam is a potent non-narcotic analgesic with supraspinal and spinal sites of action [23] and is not reversed by naloxone [24-26]. It inhibits 5-hydroxytriptamine and noradrenaline uptake [27], controls descending serotonergic pain [28], and interacts with dopaminergic pathways [29]. In addition, nefopam has analgesic effects in a rat model of neuropathy [30] with activated NMDA receptors [31]. However, while ketamine acts as an NMDA receptor antagonist to control pain, nefopam inhibits voltage-sensitive sodium channels to modulate presynaptic glutaminergic transmission [32]. 
In our present study, nefopam and ketamine equally reduced VAS and the need for fentanyl during the acute postoperative period. In addition, Group $\mathrm{N}$ showed a longer the time to the first analgesic injection in the PACU than Group C. Group $\mathrm{N}$ showed fewer analgesic injections in the ward 1 to 2 $\mathrm{h}$ after surgery, compared to Group K and Group C. These results are similar to those of other postoperative studies [33-35]. Nefopam is said to have a $30 \%-50 \%$ morphine-sparing effect and to be effective in reducing pain scores [34, 35]. In addition, nefopam is reported to reduce thermal hyperalgesia induced by plantaris muscle incision of the hind legs in rodents [36]. As described previously with ketamine, nefopam is also known to have antihyperalgesic effects [33].

However, whether the effect site concentration of $4 \mathrm{ng} / \mathrm{ml}$ remifentanil is sufficient to cause hyperalgesia remains unclear. Many studies have reported that opioid-induced hyperalgesia or acute opioid tolerance frequently occur with high-dose remifentanil infusion [37]. However, low-dose remifentanil infusion with an effect site concentration of $2 \mathrm{ng} / \mathrm{ml}$ can amplify pain in the immediate postoperative period [38]. In addition, Angst et al. [5] argued that withdrawal after exposure to a plasma concentration of remifentanil in the range of 2.7 and $2.9 \mathrm{ng} / \mathrm{ml}$ increased the pain response compared to before remifentanil was infused. Thus, remifentanil infusion according to our protocol may lead to hyperalgesia. As a result, intraoperavie nefopam infusion reduced pain and analgesic consumption in the immediate postoperative period, indicating that it may prevent remifentanil-induded pronociceptive effects.

In the previous studies, side effects including nefopam-related tachycardia, profuse sweating, and ketamine-related sedation were reported [26, 33, 35]. In our present study, Group $\mathrm{K}$ had a longer period between respiration recovery and awakening than Group N and Group C ( $\mathrm{p}=0.0132$, 0.0002), while no statistically significant difference was observed between Group $N$ and Group C $(p=0.145)$. Nonetheless, all patients in Group $\mathrm{K}$ regained consciousness easily and it was simple to measure pain levels with VAS scores. Furthermore, no problems occurred with recovery. No differences were found between Group N and Group C in terms of intraoperative hemodynamic changes, PONV, postoperative sedation, sweating, and other complications. Mimoz et al. [35] claimed that tachycardia is less likely to develop with more than 30 min of continuous infusion of nefopam; and in our present study, the average time for anesthesia was 153 min, decreasing the possibility of tachycardia.
Therefore, continuous intraoperative infusion may be superior to shorter nefopam infusion for reducing complications.

There are several limitations to this study. We did not verify whether nefopam is effective in reducing VAS scores and fentanyl requirements due to its analgesic effect or its antihyperalgesic effect. The plasma half-life of nefopam is 3 to $5 \mathrm{~h}$ and the peak plasma concentration is reached 15 to $20 \mathrm{~min}$ after intravenous injection [39]. In this study, for the first hour in the PACU, Group N had fewer VAS scores and showed less time to the first analgesic injection when compared to Group C, but the effects of nefopam were not continued throughout the $8 \mathrm{~h}$ on the ward. However, ketamine dosage has been known to have antihyperalgesic effects in remifentanil-induced hyperalgesia [14, 21, 22] and nefopam infusion was as effective as ketamine infusion in the present study. In addition, from 1 to 2 $\mathrm{h}$ after surgery in the ward, patients in Group $\mathrm{N}$ had fewer analgesic injections than Group K. Based on these results, intraoperative nefopam infusion should be effective for preventing remifentanil-induced hyperalgesia.

In conclusion, intraoperative nefopam infusion is as effective as intraoperative ketamine in reducing pain scores and fentanyl requirements during the acute postoperative period after remifentanil infusion in laparoscopic cholecystectomy.

\section{Competing Interests}

The authors have declared that no competing interest exists.

\section{References}

1. Bisgaard T. Analgesic treatment after laparoscopic cholecystectomy: a critical assessment of the evidence. Anesthesiology. 2006; 104:835-46.

2. Kehlet H, Gray AW, Bonnet F, Camu F, Fischer HB, McCloy RF, et al. A procedure-specific systematic review and consensus recommendations for postoperative analgesia following laparoscopic cholecystectomy. Surg Endosc. 2005; 19:1396-415.

3. Mandel JE. Considerations for the use of short-acting opioids in general anesthesia. J Clin Anesth. 2014; 26(Suppl 1):S1-S7.

4. Thompson JP, Rowbotham DJ. Remifentanil--an opioid for the 21st century. Br J Anaesth. 1996; 76:341-3.

5. Angst MS, Koppert W, Pahl I, Clark DJ, Schmelz M. Short-term infusion of the mu-opioid agonist remifentanil in humans causes hyperalgesia during withdrawal. Pain. 2003; 106:49-57.

6. Chu LF, Angst MS, Clark D. Opioid-induced hyperalgesia in humans: molecular mechanisms and clinical considerations. Clin J Pain. 2008; 24:479-96.

7. Servin FS, Billard V. Remifentanil and other opioids. Hand Exp Pharmacol. 2008; 182:283-311.

8. Joly V, Richebe P, Guignard B, Fletcher D, Maurette P, Sessler DI, et al. Remifentanil-induced postoperative hyperalgesia and its prevention with small-dose ketamine. Anesthesiology. 2005; 103:147-55.

9. Rosland $\mathrm{JH}$, Hole $\mathrm{K}$. The effect of nefopam and its enantiomers on the uptake of 5-hydroxytryptamine, noradrenaline and dopamine in crude rat brain synaptosomal preparations. J Pharm Pharmacol. 1990; 42:437-8.

10. Verleye M, Andre N, Heulard I, Gillardin JM. Nefopam blocks voltage-sensitive sodium channels and modulates glutamatergic transmission in rodents. Brain Res. 2004; 1013:249-55.

11. Yoo JY, Lim BG, Kim H, Kong MH, Lee IO, Kim NS. The analgesic effect of nefopam combined with low dose remifentanil in patients undergoing middle ear surgery under desflurane anesthesia: a randomized controlled trial. Korean J Anesthesiol. 2015; 68:43-9. 
12. Choi SK, Yoon MH, Choi JI, Kim WM, Heo BH, Park KS, et al. Comparison of effects of intraoperative nefopam and ketamine infusion on managing postoperative pain after laparoscopic cholecystectomy administered remifentanil. Korean J Anesthesiol. 2016; 69:480-6.

13. Richebe P, Picard W, Rivat C, Jelacic S, Branchard O, Leproust S, et al. Effects of nefopam on early postoperative hyperalgesia after cardiac surgery. J Cardiothorac Vasc Anesth. 2013; 27:427-35.

14. Hong BH, Lee WY, Kim YH, Yoon SH, Lee WH. Effects of intraoperative low dose ketamine on remifentanil-induced hyperalgesia in gynecologic surgery with sevoflurane anesthesia. Korean J Anesthesiol. 2011; 61:238-43.

15. Hang LH, Shao DH, Gu YP. The ED50 and ED95 of ketamine for prevention of postoperative hyperalgesia after remifentanil-based anaesthesia in patients undergoing laparoscopic cholecystectomy. Swiss Med Wkly. 2011; 141:w13195.

16. Song D, White PF. Remifentanil as an adjuvant during desflurane anesthesia facilitates early recovery after ambulatory surgery. J Clin Anesth. 1999; 11:364-7.

17. Song D, Whitten CW, White PF. Remifentanil infusion facilitates early recovery for obese outpatients undergoing laparoscopic cholecystectomy. Anesth Analg. 2000; 90:1111-3.

18. Hood DD, Curry R, Eisenach JC. Intravenous remifentanil produces withdrawal hyperalgesia in volunteers with capsaicin-induced hyperalgesia. Anesth Analg. 2003; 97:810-5.

19. Luginbuhl M, Gerber A, Schnider TW, Petersen-Felix S, Arendt-Nielsen L, Curatolo M. Modulation of remifentanil-induced analgesia, hyperalgesia, and tolerance by small-dose ketamine in humans. Anesth Analg. 2003; 96:726-32.

20. Gu X, Wu X, Liu Y, Cui S, Ma Z. Tyrosine phosphorylation of the N-Methyl-D-Aspartate receptor 2B subunit in spinal cord contributes to remifentanil-induced postoperative hyperalgesia: the preventive effect of ketamine. Mol Pain. 2009; 5:76.

21. Angst MS, Clark JD. Opioid-induced hyperalgesia: a qualitative systematic review. Anesthesiology. 2006; 104:570-87.

22. Koppert W, Sittl R, Scheuber K, Alsheimer M, Schmelz M, Schuttler J. Differential modulation of remifentanil-induced analgesia and postinfusion hyperalgesia by S-ketamine and clonidine in humans. Anesthesiology. 2003; 99:152-9.

23. Fasmer OB, Berge OG, Jorgensen HA, Hole K. Antinociceptive effects of (+/-)-, (+)- and (-)-nefopam in mice. J Pharm Pharmacol. 1987; 39:508-11.

24. Piercey MF, Schroeder LA. Spinal and Supraspinal sites for morphine and nefopam analgesia in the mouse. Eur J Pharmacol. 1981; 74:135-40.

25. Tresnak-Rustad NJ, Wood ME. In vitro biochemical effects of nefopam hydrochloride, a new analgesic agent. Biochem Pharmacol. 1981; 30:2847-50.

26. Heel RC, Brogden RN, Pakes GE, Speight TM, Avery GS. Nefopam: a review of its pharmacological properties and therapeutic efficacy. Drugs. 1980; 19:249-67.

27. Fuller RW, Snoddy HD. Evaluation of nefopam as a monoamine uptake inhibitor in vivo in mice. Neuropharmacology. 1993; 32:995-9.

28. Hunskaar S, Fasmer OB, Broch OJ, Hole K. Involvement of central serotonergic pathways in nefopam-induced antinociception. Eur J Pharmacol. 1987; 138:77-82.

29. Esposito E, Romandini S, Merlo-Pich E, Mennini T, Samanin R. Evidence of the involvement of dopamine in the analgesic effect of nefopam. Eur J Pharmacol. 1986; 128:157-64

30. Biella GE, Groppetti A, Novelli A, Fernandez-Sanchez MT, Manfredi B, Sotgiu ML. Neuronal sensitization and its behavioral correlates in a rat model of neuropathy are prevented by a cyclic analog of orphenadrine. J Neurotrauma. 2003; 20:593-601.

31. Kim YI, Na HS, Yoon YW, Han HC, Ko KH, Hong SK. NMDA receptors are important for both mechanical and thermal allodynia from peripheral nerve injury in rats. Neuroreport. 1997; 8:2149-53.

32. Fernandez-Sanchez MT, Diaz-Trelles R, Groppetti A, Manfredi B, Brini AT, Biella G, et al. Nefopam, an analogue of orphenadrine, protects against both NMDA receptor-dependent and independent veratridine-induced neurotoxicity. Amino Acids. 2002; 23:31-6.

33. Kapfer B, Alfonsi P, Guignard B, Sessler DI, Chauvin M. Nefopam and ketamine comparably enhance postoperative analgesia. Anesth Analg. 2005; 100:169-74.

34. McLintock TT, Kenny GN, Howie JC, McArdle CS, Lawrie S, Aitken H. Assessment of the analgesic efficacy of nefopam hydrochloride after upper abdominal surgery: a study using patient controlled analgesia. Br J Surg. 1988; 75:779-81.

35. Mimoz O, Incagnoli P, Josse C, Gillon MC, Kuhlman L, Mirand A, et al. Analgesic efficacy and safety of nefopam vs. propacetamol following hepatic resection. Anaesthesia. 2001; 56:520-5.

36. Girard P, Pansart Y, Coppe MC, Gillardin JM. Nefopam reduces thermal hypersensitivity in acute and postoperative pain models in the rat. Pharmacol Res. 2001; 44:541-5.

37. Shin SW, Cho AR, Lee HJ, Kim HJ, Byeon GJ, Yoon JW, et al. Maintenance anaesthetics during remifentanil-based anaesthesia might affect postoperative pain control after breast cancer surgery. Br J Anaesth. 2010; 105:661-7.

38. Vinik HR, Kissin I. Rapid development of tolerance to analgesia during remifentanil infusion in humans. Anesth Analg. 1998; 86:1307-11.

39. Aymard G, Warot D, Demolis P, Giudicelli JF, Lechat P, Le Guern ME, et al. Comparative pharmacokinetics and pharmacodynamics of intravenous and oral nefopam in healthy volunteers. Pharmacol Toxicol. 2003; 92:279-86. 